\title{
A modified framework for the regional assessment of climate and human impacts on net primary productivity
}

\author{
Ying Pan ${ }^{\mathrm{a}, 1}$, Chengqun Yu ${ }^{\mathrm{a}, \mathrm{b}, 1}$, Xianzhou Zhang ${ }^{\mathrm{a}, \mathrm{b}}$, Baoxiong Chen ${ }^{\mathrm{a}, \mathrm{b}}$, Junxi $\mathrm{Wu}^{\mathrm{a}, \mathrm{b}, *}$, \\ Yanli $\mathrm{Tu}^{\mathrm{c}}$, Yanjun Miao ${ }^{\mathrm{d}}$, Liming Luo ${ }^{\mathrm{d}}$ \\ a Institute of Geographic Sciences and Natural Resources Research, Chinese Academy of Sciences, Beijing 100101, China \\ ${ }^{\mathrm{b}}$ Key Laboratory of Ecosystem Network Observation and Modelling, Institute of Geographic Sciences and Natural Resources Research, Chinese Academy of \\ Sciences, Beijing 100101, China \\ ${ }^{\mathrm{c}}$ Tibet Plateau Institute of Biology, Lhasa 850001, China \\ ${ }^{\mathrm{d}}$ Agricultural and Animal Husbandry College of Tibet University, Linzhi 860000, China
}

\section{A R T I C L E I N F O}

\section{Article history:}

Received 29 August 2014

Received in revised form 9 June 2015

Accepted 14 June 2015

Available online 17 July 2015

\section{Keywords:}

$\mathrm{NPP}_{\text {gap }}$

HANPP

Plant functional traits

Precipitation legacy

Tibetan Plateau

\begin{abstract}
A B S T R A C T
Improving models that depict the components of net primary production (NPP) in ecosystems will help us to better understand how climate change and human activities affect the biosphere. In this study, NPPgap was introduced into the present human appropriation of net primary production (HANPP) framework. We introduced $\mathrm{NPP}_{\text {gap }}$ in this study as potential NPP $\left(\mathrm{NPP}_{\text {pot }}\right)$ minus the sum of ecosystem NPP ( $\left.\mathrm{NPP}_{\text {eco }}\right)$ and HANPP, which relates to the ability of models to depict NPP components. Using the Lhasa River region of the Tibetan Plateau, we examined temporal and spatial variations in the components of NPP over a 10 -year period. Results showed that $\mathrm{NPP}_{\text {pot }}$, HANPP and NPPeco increased from 2000 to 2010, but at different rates and with different spatial patterns. NPP gap each year ranged from $-9.2 \%$ to $13.1 \%$ for each site and on average composed $1.2 \%$ of the total $\mathrm{NPP}_{\text {pot }}$ NPP gap was significantly correlated with precipitation, plant biodiversity, plant height and soil properties. NPP gap increased if either of the previous 2 years had been wet years with relative high precipitation. An increase in the richness of palatable species would lead to a larger NPPgap through more compensatory growth. The large fluctuation level of NPP gap reflected the higher stability of vegetation productivity, which is caused by higher plant heights and soil maximum water capacity. This study showed the potential of the HANPP framework in regional assessment of climate and human impacts on net primary productivity. The use of the NPP gap measure reflects the gap in our knowledge and our ability to accurately estimate the components of NPP.
\end{abstract}

(ㄷ) 2015 Elsevier Ltd. All rights reserved.

\section{Introduction}

Net primary production (NPP) is the net amount of carbon accumulated by plants in a given period (Haberl et al., 2007). NPP is the fundamental ecosystem service that mediates an ecosystem's ability to supply other services, such as producing food and fiber, regulating climate and water, and supplying recreation and cultural benefits (Millennium Ecosystem Assessment, 2005). A framework of human appropriation of net primary production (HANPP) was introduced and developed to help us to understand climate and

\footnotetext{
* Corresponding author at: Institute of Geographic Sciences and Natural Resources Research, Chinese Academy of Sciences (CAS), Datun Road 11A, Chaoyang District, Beijing 100101, China. Tel.: +86106488 8157; fax: +86106488 8157.

E-mail address: wujx@igsnrr.ac.cn (J.Wu).

1 These authors contributed equally to this work.
}

human impacts on ecosystems (Wright, 1990; Haberl, 1997; Imhoff et al., 2004; Haberl et al., 2007, 2014). HANPP is defined as the difference between the NPP of the natural vegetation thought to exist in the absence of land use (Haberl et al., 2014). In the latest definition, HANPP equals the NPP of potential natural vegetation (NPP ot $)$ minus the NPP remaining in the ecosystem after harvest under current conditions (NPP eco $_{\text {) }}$ (Haberl et al., 2014). HANPP comprises the harvested NPP ( HANPP $\left._{\text {harv }}\right)$ and changes in NPP resulting from land conversion and land use (HANPP luc $_{\text {luc }}$ (Haberl et al., 2014).

HANPP is an indicator of the extent of human interference on the NPP partitioning process. HANPP has, in general, been calculated at the global scale. Global HANPP doubled in the 20th century, comprising $24 \%$ of potential NPP in 2000 , of which $53 \%$ was harvested, $40 \%$ lost as a result of changes in land use, and $7 \%$ lost in human-induced fires (Haberl et al., 2007; Krausmann et al., 2013). The global HANPP quantification showed us the tremendous scale of human intervention on ecosystems. 
Applying the HANPP framework at a regional scale can quantify the NPP loss by human intervention in more detail but, more importantly, find ways to optimize ecosystem management. The HANPP framework can be used to underpin regional sustainability, based on a detailed understanding of the impact of climatic change and human activities on net primary productivity (Cardoch et al., 2002; Mao et al., 2014). For HANPP to be an effective tool, the global HANPP framework needs to be amended and developed in line with the regional differences in climate and human activities.

The Tibetan Plateau is the highest plateau in the world with a dominant ecosystem of alpine grassland, which supports both the livelihood of local residents and the hydrological and carbon cycles of the Asia continent (Pan et al., 2014). In the shoot-root-soil system of an alpine meadow on the Tibetan Plateau, 58.3\% of total assimilated carbon was transferred to belowground pools, which was much higher than the proportion in perennial grasses, such as ryegrass (Wu et al., 2010). Grazing in this system could possibly lead to less carbon being lost through shoot respiration and more being translocated belowground (Hafner et al., 2012). However, increased human populations and grazing activities consumed an increasing amount of aboveground NPP, leaving less in the ecosystem. This could lead to tradeoffs between regional ecosystem provisioning and regulating services (Pan et al., 2014). Vegetation change due to climate change may also lead to a more difficult situation for decision makers trying to balance support for local livelihoods and for the continent's environment. The HANPP framework plays an important role in quantifying the impacts of climate change and grazing on vegetation dynamics. However, the framework needs to be downscaled from the global scale to account for variations in the dominant human activity of livestock grazing and the regional climate.

Local quantification of each part of NPP is the key purpose of the regional application of the HANPP framework. Of the total NPP, climatic potential NPP $\left(\mathrm{NPP}_{\text {pot }}\right)$ refers to the maximum NPP driven by climatic factors, which includes the NPP consumed or lost by human activities, and the NPP left in the ecosystem (Chen et al., 2014). $\mathrm{NPP}_{\text {pot }}$ can be simulated by models (Adams et al., 2004), including biogeographical (correlative) models such as Miami (Lieth, 1975) and BIOME (Prentice et al., 1992), and biogeochemical (processbased) models such as the Terrestrial Ecosystem Model (TEM) (Chen et al., 2014; Raich et al., 1991). Ecosystem NPP (NPPeco) is the fraction of NPP remaining in the ecosystem after human intervention (Haberl et al., 2014). NPPeco can be simulated with the Carnegie-Ames-Stanford Approach (CASA) model (Chen et al., 2014; Field et al., 1995; Potter et al., 1993), or estimated using a Moderate Resolution Imaging Spectroradiometer (MODIS). NPPeco

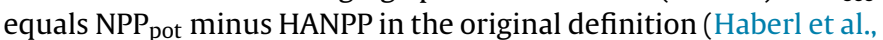
2014). NPP eco is connected with the supply of many regulating services, such as water regulation, carbon sequestration and soil retention (Pan et al., 2014).

Gaps remain in our knowledge of NPP and this has limited model accuracy. For example, there is a time lag associated with the response of NPP pot to precipitation changes (Jin and Goulden, 2014; Lauenroth and Sala, 1992; Peters et al., 2012, 2014; Reichmann et al., 2013; Sala et al., 2012). In addition, current HANPP models seldom include the feedback of harvest or land use to the ecosystem, including the fertilizing effects of grazing animals (Xu et al., 2013) and the compensatory growth of damaged plant tissue (Hawkes and Sullivan, 2001; Leriche et al., 2001, 2003; Schonbach et al., 2011; Wise and Abrahamson, 2007). These knowledge gaps may lead to estimation errors because $\mathrm{NPP}_{\text {pot }}$ may not equal the sum of NPPeco and HANPP.

In this study, we introduced an NPP gap into the current HANPP framework. We attempted to find the temporal and spatial patterns of NPPgap in the context of changing climate and human activities. Further, we attempted to identify how ecosystem properties, biodiversity, plant functional traits and soil properties affect the heterogeneous patterns of $\mathrm{NPP}_{\text {gap }}$. The aim of introducing $\mathrm{NPP}_{\text {gap }}$ is to improve the NPP simulation in the HANPP framework via the consideration of precipitation legacies and grazer-driven compensatory plant growth.

\section{Materials and methods}

\subsection{Theoretical framework}

The net primary production includes four components of $\mathrm{NPP}_{\text {pot, }}$, HANPP, NPPeco and NPP gap (Fig. 1). NPP gap was proposed in this study to be $\mathrm{NPP}_{\text {pot }}$ minus the sum of NPPeco and HANPP. NPP pot was simulated by a process-based model, representing the regional maximum NPP, only affected by climate change. HANPP comprise harvest biomass ( HANPP $\left._{\text {harv }}\right)$ and biomass loss from land conversion and land use $\left(\right.$ HANPP $\left._{\text {luc }}\right)$ (Haberl et al., 2014). HANPP $_{\text {harv }}$ was calculated based on meat production and cattle breeding, representing the NPP lost to grazing. HANPP ${ }_{\text {luc }}$ were not considered in this study because there was no land conversion in last decade of the sampling area. NPPeco is the NPP remaining in ecosystem supplying ecosystem regulating services. For this study, we assumed that the $\mathrm{NPP}_{\text {gap }}$, including the mean value and the fluctuation level, was affected by ecosystem properties, plant functional traits, plant diversity, soil properties and precipitation in previous years, as precipitation legacies (Reichmann et al., 2013; Sala et al., 2012) and the compensatory growth (Leriche et al., 2003) may play an important role in NPP.

\subsection{Study region}

The Lhasa River region lies in the south of the Tibetan Plateau, and in the center of the Tibet Autonomous Region $\left(29^{\circ} 0^{\prime}-31^{\circ} 45^{\prime} \mathrm{N}\right.$, $90^{\circ} 1^{\prime}-94^{\circ} 10^{\prime} \mathrm{E}$ ), comprising eight counties (Fig. 2). The altitude ranges from 3563 to $6836 \mathrm{~m}$. Grasslands occupy $70 \%$ of the total area in this region, mostly alpine meadows with small areas of warm steppe in the river valley areas. Not much land-use conversion has occurred in the last decade of the whole Lhasa River region, only $0.17 \%$ land converted from grassland to wet land and $0.08 \%$ from grassland to settlements. And no land converted in the sampling area. The mean annual precipitation was $594 \mathrm{~mm}$ in 2010 and has been decreasing by an average of $13.36 \mathrm{~mm}$ each year since 2000 . The mean air temperature in 2010 was $-0.49^{\circ} \mathrm{C}$ and has been increasing by an average of $0.10^{\circ} \mathrm{C}$ annually since 2000 (Fig. $3 \mathrm{~b}$ and Table 1). The main human impact on NPP in this region is grazing, specifically by yak, sheep and goats. Overgrazing is a common problem in recent years as the livestock inventories increased steadily from 2001 to 2008 , although numbers decreased from 2008 to 2010 , possibly related to ecological compensations implemented around 2003 (Chen et al., 2014).

\subsection{Data collection and processing}

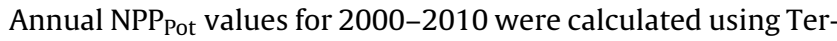
restrial Ecosystem Model (TEM), as described in Chen et al. (2014), using a pixel level of $1 \mathrm{~km} \times 1 \mathrm{~km}$. Annual NPPeco (also using a pixel level of $1 \mathrm{~km} \times 1 \mathrm{~km}$ ) from 2000 to 2010 were taken from MODIS 17A3(Smith et al., 2014) (http://e4ftl01.cr.usgs.gov/MOLT/). Annual precipitation and air temperature data (Fig. 2) were retrieved from the China Meteorological Administration (http://www.cma.gov. $\mathrm{cn} /$ ) and interpolated to pixel data with spatial resolution of $1 \mathrm{~km}$ using ANUSPLIN ver. 4.2 (Chen et al., 2014). Yak, sheep and goat stocks and meat production at the county level were taken from Tibetan year books (2001-2011). All stock data were converted to sheep units, with one yak equaling four sheep units and one sheep or goat equaling one sheep unit, and then transformed to 


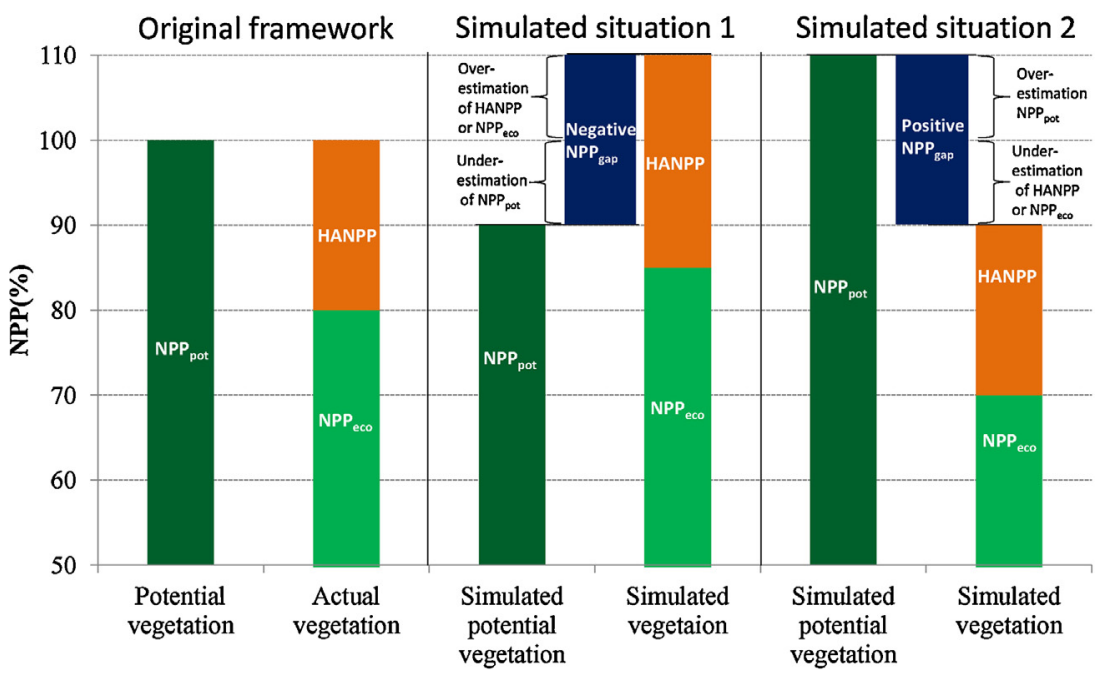

Source: Modified based on Fig. 1 in Haberl et al. (2014).

Fig. 1. Theoretical framework of the calculation of the $\mathrm{NPP}_{\text {gap }}$.

Table 1

Spatial heterogeneity of the temporal variation trends of climate, human activity change and the response of NPP.

\begin{tabular}{|c|c|c|c|c|c|}
\hline Variation trends from 2000 to 2010 & Unit & Min & Max & Mean & Standard deviation \\
\hline Precipitation & $\mathrm{mma}^{-1}$ & -20.45 & -5.12 & -13.36 & 3.79 \\
\hline Air temperature & ${ }^{\circ} \mathrm{Ca}-1$ & 0.07 & 0.13 & 0.10 & 0.01 \\
\hline $\mathrm{NPP}_{\text {pot }}$ & $\mathrm{gCm}^{-2} \mathrm{a}^{-1}$ & -38.15 & 16.20 & 0.14 & 2.73 \\
\hline $\mathrm{NPP}_{\text {eсо }}$ & $\mathrm{gCm}^{-2} \mathrm{a}^{-1}$ & -21.61 & 13.34 & 1.09 & 1.76 \\
\hline HANPP of livestock inventories & $\mathrm{gCm}^{-2} \mathrm{a}^{-1}$ & -0.89 & 0.95 & 0.28 & 0.18 \\
\hline HANPP of meat production & $\mathrm{gCm}^{-2} \mathrm{a}^{-1}$ & 0.24 & 2.03 & 1.04 & 0.47 \\
\hline $\mathrm{NPP}_{\text {gap }}$ & $\mathrm{gCm}^{-2} \mathrm{a}^{-1}$ & -38.76 & 16.79 & -3.05 & 2.51 \\
\hline
\end{tabular}

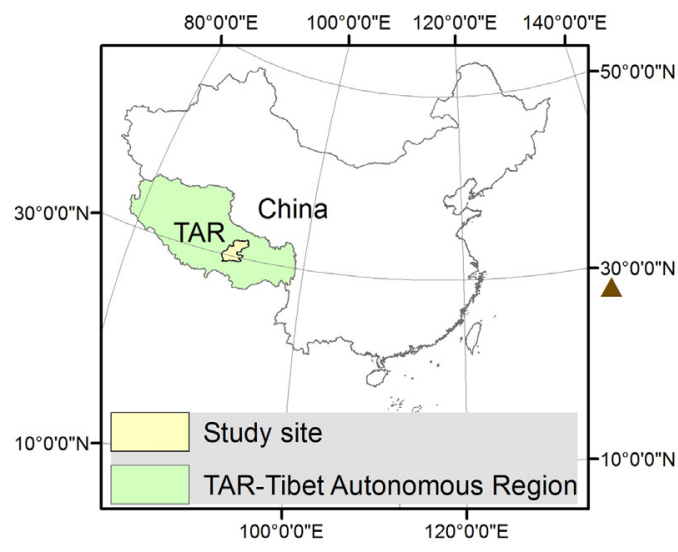

- Weather stations

- $\quad$ Sampling points

- Rivers

Sub-catchments

Study site

$\Delta$

$\Delta$

$\triangle$

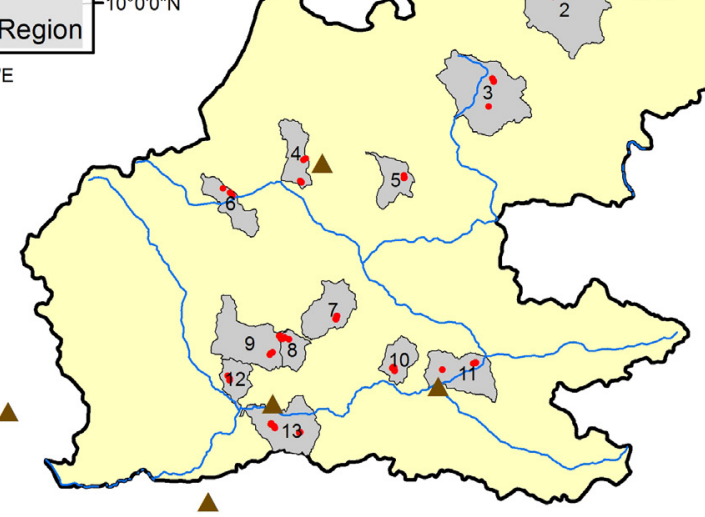

$\Delta$

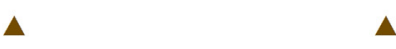

$\Delta$

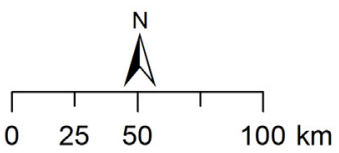

Fig. 2. Study region (numbers 1-13 indicate the IDs of the sub-catchments). 

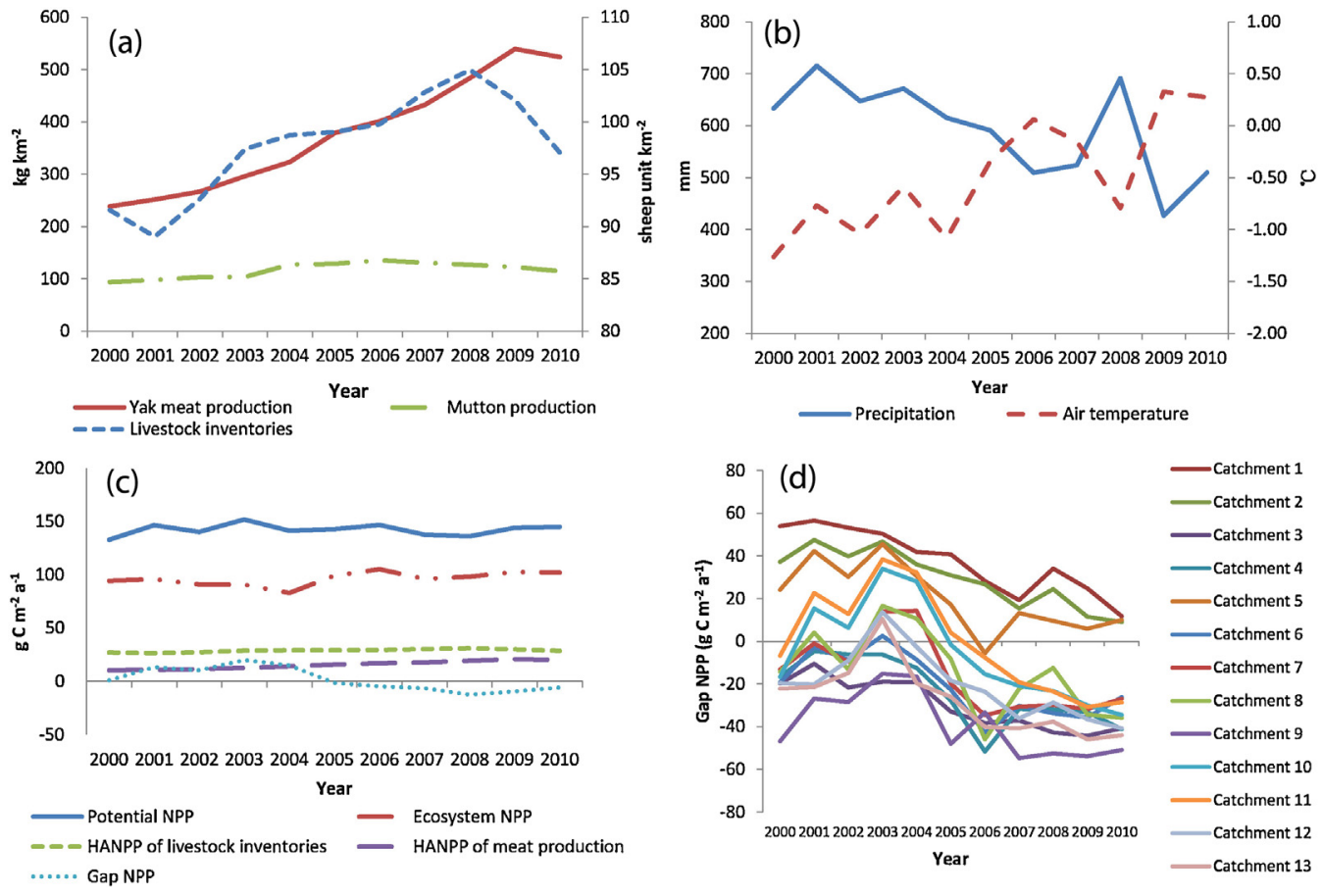

Fig. 3. Temporal variation of the climate, human activity, the potential and ecosystem NPP of the study site.

geographic (pixel) data. HANPP luc was assumed to be 0 , because no grassland was converted in the last decade, and there was no forest in the sampling area. The HANPP harv $_{\text {comprises the HANPP }}$ of livestock inventories and meat production (Eqs. (1)-(5)).

$\mathrm{HANPP}=\mathrm{HANPP}_{\text {harv }}+\mathrm{HANPP}_{\text {luc }}$
$\mathrm{HANPP}_{\text {harv }}=\mathrm{HANPP}_{\text {Livestock inventories }}+\mathrm{HANPP}_{\text {Meat }}$ production

HANPP $_{\text {Livestock inventories }}=0.45 \times$ livestock inventories

$$
\times \text { daily intake of one sheep unit }
$$

The daily intake of one sheep unit is $1.8 \mathrm{~kg}$ dry matter (Ministry of Agriculture of the People's Republic of China, 2002), and 0.45 is the coefficient to transform dry matter to carbon.

HANPP $_{\text {Meat production }}=0.45 \times($ yak meat production

$$
\begin{aligned}
& \times \text { coefficient yak }+ \text { mutton meat production } \\
& \times \text { coefficient sheep) }
\end{aligned}
$$

Coefficient yak and sheep are 71.38 and 65.07, respectively (Pan et al., 2014).

The annual NPPgap from 2000 to 2010 was calculated as Eq. (4).

$$
\mathrm{NPP}_{\text {gap }}=\mathrm{NPP}_{\text {pot }}-\mathrm{HANPP}-\mathrm{NPP}_{\text {eco }}
$$

Variation trends (slope) of precipitation, air temperature, $\mathrm{NPP}_{\text {pot }}, \mathrm{NPP}_{\text {eco, }}$ HANPP and NPP gap at pixel level were calculated as the best-fit slopes of the linear regressions (Eq. (6)) (Chen et al., 2014). The standard deviations of the variation of the NPPgap from 2000 to 2010 were also calculated to reflect the fluctuations in NPP gap.

Slope $_{\text {data }}=\frac{n \times \sum_{i=1}^{n}\left(i \times \text { data }_{i}\right)-\sum_{i=1}^{n} i \times \sum_{i=1}^{n} \text { data }_{i}}{n \times \sum_{i=1}^{n} i^{2}-\left(\sum_{i=1}^{n} i\right)^{2}}$

Slope $_{\text {data }}$ is the variation trends of NPP, climate or human activities, where $n$ represents the sequential years and data $_{i}$ is the precipitation, air temperature, $\mathrm{NPP}_{\text {pot }}, \mathrm{NPP}_{\text {eco }}, \mathrm{HANPP}$ or $\mathrm{NPP}_{\text {gap }}$ in the year $i$.

The impact of precipitation fluctuation on the NPPgap of current year was analyzed. The precipitation fluctuation was defined assuming precipitation legacies (Reichmann et al., 2013; Sala et al., 2012). In this study, a change in precipitation was used calculated by the precipitation of the previous year minus the current year or the precipitation of 2 years ago minus the current year. The correlation analysis between NPP gap and change in precipitation in each catchment was done for each year and additional analyses were conducted for NPP gap in 2003, 2005, 2007, 2010 and the change in precipitation for the previous 2 years (2001-2003, 2003-2005, 2005-2007, 2008-2010) (Fig. 3d). Sub-catchments were divided with soil and water assessment tools (SWAT), and 13 catchments were selected randomly. The mean value, mean variation trends and standard deviation of precipitation, air temperature, NPP pot, NPP eco, HANPP and NPP of each catchment were calculated.

Soil and plant samples were taken in each catchment in 2012. Five or six sampling plots of $5 \mathrm{~m} \times 5 \mathrm{~m}$ were set up in each catchment. Three plant samples were taken in each $0.5 \mathrm{~m} \times 0.5 \mathrm{~m}$ subplot. Plants were identified to species, categorized as palatable or unpalatable and measured, including their aboveground biomass, height and vegetation cover. The dominant and subdominant species in each plot were categorized according to their degree of vegetation cover.

Three soil profiles $(0-30 \mathrm{~cm})$ were excavated per sampling area. Soil samples were taken with cutting rings (diameter $50.46 \mathrm{~mm}$, height $50 \mathrm{~mm}$, volume $100 \mathrm{~cm}^{3}$ ) and soil water content, soil maximum water holding capacity, root density, organic carbon, total nitrogen and phosphorus were measured in the laboratory. Soil maximum water holding capacity was measured by placing the soil samples, still in the cutting rings, in water for $12 \mathrm{~h}$, weighing the saturated sample, drying it at $105^{\circ} \mathrm{C}$ for $24 \mathrm{~h}$ and then subtracting the dry weight.

Total cover, aboveground biomass and root density were the variables used to indicate ecosystem properties. Richness of all species, richness of palatable species, and the ratio of palatable to all species were the variables used to indicate ecosystem 
biodiversity. Soil water content, soil maximum water capacity, soil bulk density, total organic carbon, total nitrogen, and total phosphorus were the variables used to indicate soil properties. Plant height and palatability were chosen as two plant-functional traits. A community weighted mean value (CWM) and Rao's index of plant heights were used to quantify the plant functional traits of plant heights (Eqs. (7) and (8)) (Diaz et al., 2007; Leps et al., 2006).

$C W M=\sum_{i=1}^{s} d_{i} p_{i}$

Rao $=\sum_{i=1}^{s} \sum_{j=1}^{s} d_{i j} p_{i} p_{j}$

The number of species in one sampling plot is denoted by $s ; d_{i}$ is the value of the functional trait (plant height) of species $i ; d_{i j}$ is the difference of the value of functional traits of species $i$ and $j, P_{i}$ and $P_{j}$ are the proportion of vegetation cover of species $i$ or $j$ to the total cover of one plot.

\section{Results}

\subsection{Temporal and spatial variation of NPP components due to} changes in climate and human activity

Climate was variable between 2000 and 2010, but generally precipitation decreased while air temperature increased (Fig. $3 \mathrm{~b}$ and Table 1). Three years were characterized by warmth and drought (2006, 2007 and 2009), while all other years were cold and wet.

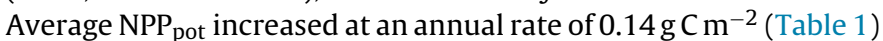
and $\mathrm{NPP}_{\text {eco }}$, based on satellite images, increased at an annual rate of $1.09 \mathrm{~g} \mathrm{C} \mathrm{m}^{-2}$. However, NPPeco was not consistent across all study sites and one site had a decrease in NPPeco at the rate of $-21.61 \mathrm{~g} \mathrm{C} \mathrm{m}^{-2}$ per year.

Human activities increased from 2001 to 2008, then decreased until 2010. Yak production increased while sheep and goat production remained constant. These trends correlated to a HANPP increase of $1.32 \mathrm{~g} \mathrm{C} \mathrm{m}^{-2} \mathrm{a}^{-1}$ (Table 1 ) across all study areas. However, not all sites had increased HANPP and the biggest decrease of HANPP was $-0.89 \mathrm{~g} \mathrm{C} \mathrm{m}^{-2} \mathrm{a}^{-1}$.

From 2000 to 2005, the NPP gap averaged $11.9 \mathrm{~g} \mathrm{C} \mathrm{m}^{-2} \mathrm{a}^{-1}$, but after 2005 the average was $-6.8 \mathrm{~g} \mathrm{C} \mathrm{m}^{-2} \mathrm{a}^{-1}$ (Fig. 3c). The mean annual NPP gap ranged from $-9.2 \%$ to $13.1 \%$ with an average $\mathrm{NPP}_{\text {gap }}$ that was $1.2 \%$ of $\mathrm{NPP}_{\text {pot }}$ for the study period. NPP gap was variable, with a standard deviation of 2.51 (Table 1 ). The maximum annual increase in $\mathrm{NPP}_{\text {gap }}$ was $16.79 \mathrm{~g} \mathrm{C} \mathrm{m}^{-2}$ and the maximum annual decrease was $-38.76 \mathrm{~g} \mathrm{C} \mathrm{m}^{-2}$, with a mean value of $-3.05 \mathrm{~g} \mathrm{C} \mathrm{m}^{-2}$ per year for 2000-2010. Among the 13 catchments, the NPP gap of two catchments were consistently positive and two were consistently negative, while all others decreased.

\subsection{Impact of precipitation fluctuation on the NPP gap}

This analysis aimed to test if high precipitation had legacy effects on NPP gap in later years. There was no drought year following by two wet years, so test was not done for a potential legacy effect due to low precipitation.

The NPP gap in 2006 and 2007 were significantly positively correlated with precipitation of the year 2005 minus 2006 and 2005 minus 2007 respectively. The larger change in precipitation that results from a wet year followed by drier years correlated with higher NPPgap. For most catchments in 2006 and 2007, the larger change in precipitation led to $\mathrm{NPP}_{\text {gap }}$ increasing from negative to close to 0 (Fig. 4). Additionally, high precipitation was correlated not only with the NPP gap of the current drought year, but the NPP gap

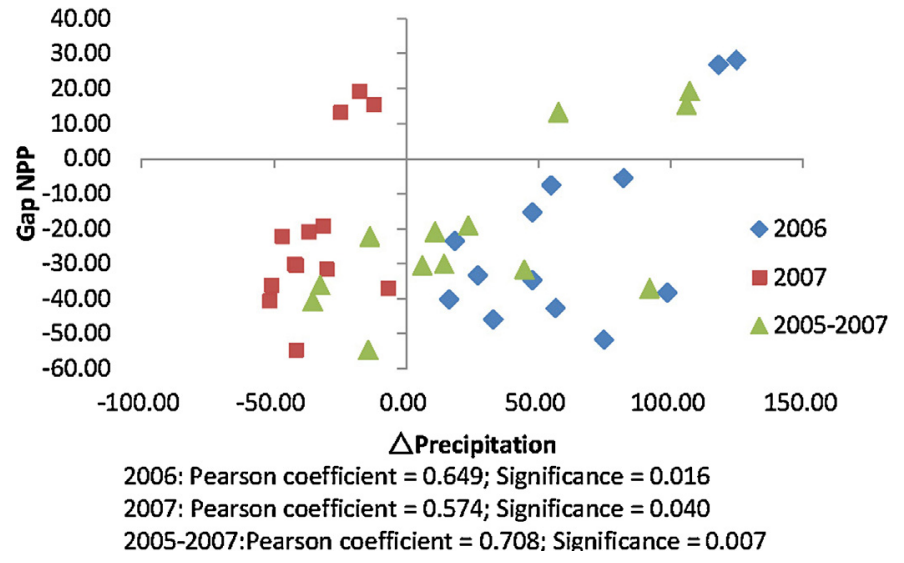

Fig. 4. Pearson correlation between gap NPP and $\Delta$ precipitation. $\Delta$ Precipitation equals the precipitation of the previous year, or two years previous minus the current year; the dots of 2006 and 2007 were the scatter plots of gap NPP of 2006 and 2007 with $\Delta$ precipitation of 2005 minus 2006 and 2006 minus 2007; the dots of 2005-2007 was the scatter plot of the gap NPP of 2007 with $\Delta$ precipitation of 2005 minus 2007.

of the following year. NPP gap in 2007 was also significantly positively correlated with the change in precipitation between 2006 (a drought year) and 2007. For most catchments in 2007, smaller changes in annual or biannual precipitation were correlated with $\mathrm{NPP}_{\text {gap }}$ increasing from negative to close to 0 .

\subsection{Impacts of biodiversity, plant functional traits and soil properties on the NPPap}

Pearson correlation analyses were conducted between the sampled indicators and the mean value of NPPgap, as well as the standard deviation of temporal variation of $\mathrm{NPP}_{\text {gap }}$ of the last decade. Among the three indicators of biodiversity, only the ratio of richness of the palatable species to all species was correlated with the mean value of NPPgap, while neither the richness of palatable species nor the total species richness had significant impacts on the mean value of $\mathrm{NPP}_{\text {gap }}$. None of the other 17 indicators belonging to plant functional traits and soil properties had significant impacts on the mean value of NPP gap (Appendix Table S1).

Three of the six indicators of soil properties significantly correlated with the standard deviation of temporal variation of NPPap-soil maximum water capacity, soil total organic carbon and nitrogen. Two plant functional traits significantly correlated with the standard deviation of temporal variation of $\mathrm{NPP}_{\text {gap }}$-the Rao and CWM of the plant heights of all species and the CWM of the plant heights of dominant species. None of the indicators of ecosystem properties or the indicators of plant functional traits had significant correlations with a mean $\mathrm{NPP}_{\text {gap }}$, nor the standard deviation of NPP gap.

Across all catchments, as the ratio of richness of the palatable species to all species increased, the mean value of $\mathrm{NPP}_{\text {gap }}$ increased from negative to close to 0 (Fig. 5a). As the Rao and CWM of plant heights of all species and soil maximum water capacity increased, the standard deviation of temporal variation of $\mathrm{NPP}_{\text {gap }}$ increased (Fig. 5b-d) and as the total organic carbon and nitrogen of soil increased, the standard deviation of $\mathrm{NPP}_{\text {gap }}$ decreased (Fig. 5e-f).

\section{Discussions}

\subsection{The gap in the simulation of potential NPP}

The NPP ${ }_{\text {gap }}$ reflects the calculation error in the NPP components estimations. In this study, we focus on the two ecological processes which were not adequately depicted in applied method. One is the 

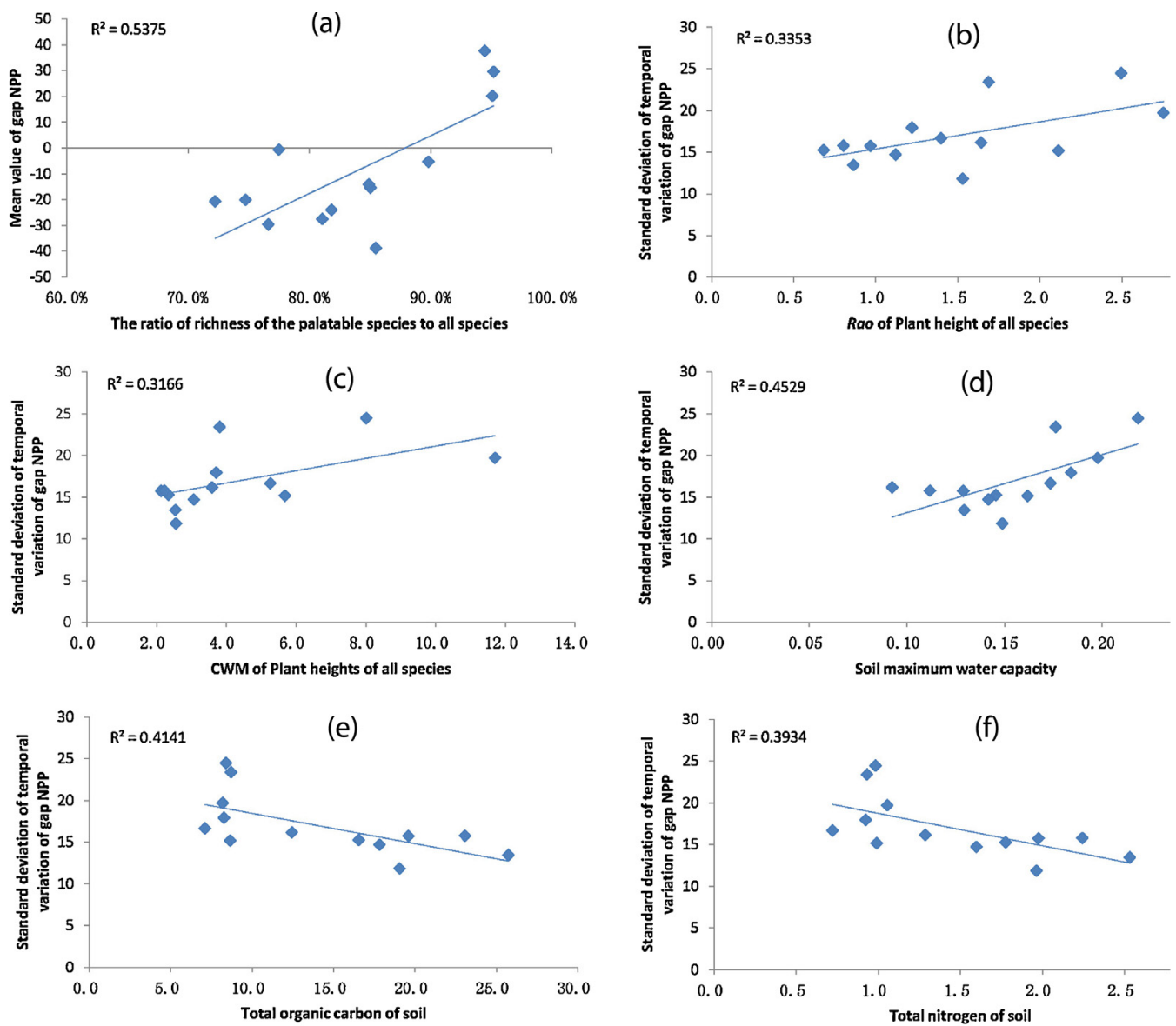

Fig. 5. Scatter diagrams of the six key factors affected the mean value and standard deviation of gap NPP.

inadequate consideration of precipitation legacy of previous years on $\mathrm{NPP}_{\text {pot }}$. The other is the compensatory plant growth as a result of grazing, and in this study, we argue that it is a feedback of HANPP on NPP pot.

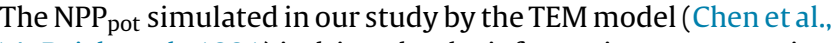
2014; Raich et al., 1991) is driven by the information on vegetation type, soils, elevation, water availability and climate (Chen et al., 2014). However, this climate data are based on the current year ignoring the potential existence of lag time in NPP response, which may be several days to several years, depending on factors such as vegetation types and soil properties (Jin and Goulden, 2014; Lauenroth and Sala, 1992; Peters et al., 2012, 2014; Reichmann et al., 2013). Sala et al. (2012) suggested the presence of precipitation legacies, whereby dry legacies reduce aboveground NPP (ANPP), while wet legacies increase ANPP. Precipitation legacies could affect a significant fraction of NPP (Sala et al., 2012), which could help explain the existence of NPPgap. In our study, the wet year (2005) was correlated with higher potential NPP in 2006 and 2007. The increased potential NPP was not simulated by the TEM model.

However, in our study, the NPP gap was only significantly correlated with change in precipitation in 2 years, suggesting other factors affect the NPP more than recent precipitation fluctuations. Bisigato et al. (2013) suggested that soil water content explained more of the temporal variation in ANPP than precipitation of current year because soil acts as a capacitor, accumulating water during wet years and releasing it during drought years (Bisigato et al., 2013). In our study, not the soil water content, but the soil water maximum capacity significantly correlated with the standard deviation of $\mathrm{NPP}_{\text {gap }}$, and higher soil water maximum capacity was correlated with decreased fluctuation in $\mathrm{NPP}_{\text {eco. }}$.

\subsection{The gap in the calculation of HANPP}

The feedbacks of HANPP, such as compensatory plant growth as a result of grazing (Haberl et al., 2007; Leriche et al., 2003) were not considered, and can potentially contribute to NPP gap. Compensatory plant growth means that some plant species are able to recover from defoliation by herbivores and even increase growth after defoliation (van Staalduinen et al., 2010). This effect may be caused by increased photosynthesis, the removal of old and dead tissue, altered mass allocation, and the production of more reproductive tillers through grazing activities (Zhao et al., 2008; Han et al., 2014). This effect seems to be enhanced in years of high seasonal precipitation (Schonbach et al., 2011).

A semi-arid steppe grassland with grazing intensities which remove $40 \%$ of aboveground mass, showed entirely compensatory growth (Zhao et al., 2008), which means that compensatory growth may lead to a maximum $40 \%$ underestimation of potential aboveground biomass. In our study, the NPP gap occupied $-9.2 \%$ to $13.1 \%$ of the $\mathrm{NPP}_{\text {pot }}$, which was a combined consequence of compensatory growth and precipitation legacies.

In addition, an increase in palatable species in the plant communities could both reduce the herbivore consumption of the most preferred species and increase the consumption of other less preferred species (Wang et al., 2010a,b, 2011). This could result in more compensatory growth of the favored species (Walter et al., 2012) and a higher NPP $_{\text {gap }}$. This explained why the ratio of 
richness of palatable species to all species was significantly positively correlated with NPPap.

\subsection{The affecting factors of the fluctuations of NPP gap}

Fluctuations of precipitation and temperature result in the fluctuation of $\mathrm{NPP}_{\text {pot }}$. Large fluctuations of $\mathrm{NPP}_{\text {gap }}$ implies a large fluctuation in $\mathrm{NPP}_{\text {pot }}$ and a small fluctuation in $\mathrm{NPP}_{\text {eco, }}$ while HANPPs increased stably. It can be argued that large fluctuations in $\mathrm{NPP}_{\text {gap }}$ are evidence of the stability of vegetation productivity under large climate fluctuations. Besides the positive effects of soil water maximum capacity (see Section 4.1), the Rao and CWM values of plant height of all species were positively correlated with $\mathrm{NPP}_{\text {gap }}$ fluctuations, suggesting stable vegetation productivity. Plant height enables greater light capture and therefore higher productivity (Vojtech et al., 2008). Rao values for plant height, our indicator of functional divergence, reflected the degree of overlap in potential productivity, while the CWM values reflected the average level of potential productivity of the communities (Diaz et al., 2007). An increase in functional divergence may correlate with higher NPPgap fluctuations, which would mean a more stable productivity. All species, regardless of dominance, affect the fluctuation of NPPgap and vegetation productivity, as proposed by the niche complementarity mechanism and insurance mechanism (Cardinale et al., 2007; Diaz et al., 2006).

The tolerance of communities to herbivore damage also affects vegetation productivity and is related to soil nutrient availability (Wise and Abrahamson, 2007). The compensatory continuum hypothesis $(\mathrm{CCH})$ states that compensatory growth, depending on the type and amount of tissue damaged, will be higher when plants are in high resource conditions, whereas the growth rate model (GRM) states the opposite and the limiting resource model (LRM) states that growth depends on the resources and herbivore (Hawkes and Sullivan, 2001; Wise and Abrahamson, 2007). In our study, lower organic carbon and total nitrogen were correlated with larger NPP gap, in line with GRM and LRM (Wise and Abrahamson, 2007).

\subsection{The implications of $N P P_{\text {gap }}$ on the improvements of NPP simulation}

A negative $\mathrm{NPP}_{\text {gap }}$ means either underestimation of $\mathrm{NPP}_{\text {pot }}$ or overestimation of HANPP, or both. The underestimation of $\mathrm{NPP}_{\text {pot }}$ might be the result of not taking into account the high precipitation legacy of previous years (Sala et al., 2012). The overestimation of HANPP might be the result of not taking into account compensatory plant growth as a result of grazing. A positive NPP gap can be evidence of either overestimation of NPP pot or underestimation of HANPP, or both. The underestimation of HANPP was not a focus of this study, such as biomass loss by cattle trampling (Dunne et al., 2011).

Simulation uncertainties existed in the calculation of NPP components, which also contributes to NPPgap (Lauenroth et al., 2006; Ruppert and Linstadter, 2014). The inconsistent primary data and simulating models of NPP components can lead to under or overestimation of NPP components. In detail, the simulations of NPP pot and $\mathrm{NPP}_{\text {eco }}$ were at pixel level, the calculations of HANPP were at county level, and the affecting factors of NPP gap were gained from plot sampling at catchment level. To minimize uncertainty, all data were aggregated to catchment level. There might be some double counting of the HANPP livestock inventories $_{\text {and HANPP }}$ meat production, such as one cattle was grazing for the whole year and slaughtered at the end of the year. This double counting may be responsible for the overestimation of HANPP.

MODIS NPP data was based on the daily remotely sensed surface reflectance (Heinsch et al., 2003). For any particular day, it is difficult to distinguish whether the sensed surface reflectance was pre-grazing or post-grazing, which could potentially contribute to the daily $\mathrm{NPP}_{\text {gap. }}$. However, the grassland was under continuous grazing pressure over the whole growing season. We believe that, on an annual scale, the remotely sensed data does accurately reflect the NPP level of a post-grazed/post-harvest grassland, which equals the NPPeco (Chen et al., 2014).

However, we contend that in our study, under- or overestimation of NPP components is likely to be constant throughout time and space, at least in the period of one decade and within one watershed. Temporal variation trends, fluctuation levels and spatial heterogeneity of the NPP components were taken into account in the paper, rather than absolute values, to minimize the simulation uncertainty.

Despite the above described uncertainty, the simulation of $\mathrm{NPP}_{\text {pot }}$ will benefit by introducing an adjustment parameter of gap $\mathrm{NPP}_{\text {pot }}$. The gap NPP pot should be established and simulated based on precipitation of at minimum the previous 2 years as well as the soil water maximum capacity. Although the $\mathrm{NPP}_{\text {gap }}$ did not show significant correlation for a wet year following drought years in our study, drought legacies of precipitation have been shown in previous studies (Sala et al., 2012), and should be considered.

HANPP estimates could be improved by introducing the feedback parameter. This feedback parameter should at least include the NPP of compensatory growth as a result of grazing. It could be simulated by LRM models and also could be simulated by a regression among NPP gap and the ratio of richness of the palatable species to all species, Rao and CWM of plant height of all species, total organic carbon and nitrogen of soil.

Compared with other HANPP analyses in which the HANPP luc dominate the HANPP signal (Krausmann et al., 2013; Smith et al., 2014), the major causes of HANPP in our study were grazing activities. The HANPP framework shows us that grazing intensity should be adjusted according to the climate to achieve a balance of HANPP and $\mathrm{NPP}_{\mathrm{eco}}$, which means the balancing local livelihood support and regional environment sustainability. As such, grazing activities can be increased in high precipitation years, which have higher $\mathrm{NPP}_{\text {pot }}$ and compensatory growth, and reduced or supplemented by imported forage from other regions during drought years.

\section{Conclusions}

$\mathrm{NPP}_{\text {gap }}$ was introduced into the present HANPP framework to implement regional assessments according to regional climate change and dominant grazing activities. The presence of an NPP gap reveals the gap in our knowledge of primary productivity and our ability to accurately estimate the accumulation and partitioning of NPP. This gap could be reduced by integrating precipitation data from previous years into simulations of $\mathrm{NPP}_{\text {pot }}$, and by calculating the feedback of human activities into calculations of HANPP, such as compensatory growth. Furthermore, the fluctuation levels of $\mathrm{NPP}_{\text {gap }}$ may reflect the stability of vegetation productivity. The regional application of the modified HANPP framework will be able to support decision makers by indicating how much the grazing intensity should be adjusted according to the climate conditions to balance HANPP and NPPeco.

\section{Acknowledgements}

We thank the anonymous reviewers and editors for their helpful comments and contributions on earlier versions of the manuscript. We also thank Guanfeng Zhao and Yan Zhao for their assistance with the field surveys. This work was supported by the National Natural Science Foundation of China (31200364), the National Science \& Technology Pillar Program during the Twelfth Five-year Plan 
Period (2011BAD17B05-4), the strategic leading science and technology projects of Chinese Academy of Sciences (B-XDB03030401) and the The Light of West" Personnel Training Program (20100309).

\section{Appendix A. Supplementary data}

Supplementary data associated with this article can be found, in the online version, at http://dx.doi.org/10.1016/j.ecolind.2015. 06.017

\section{References}

Adams, B., White, A., Lenton, T.M., 2004. An analysis of some diverse approaches to modelling terrestrial net primary productivity. Ecol. Modell. 177, 353-391.

Bisigato, A.J., Hardtke, L., del Valle, H.F., 2013. Soil as a capacitor: considering soil water content improves temporal models of productivity. J. Arid Environ. 98, 88-92.

Cardinale, B.J., Wright, J.P., Cadotte, M.W., Carroll, I.T., Hector, A., Srivastava, D.S., Loreau, M., Weis, J.J., 2007. Impacts of plant diversity on biomass production increase through time because of species complementarity. Proc. Natl. Acad. Sci. U. S. A. 104, 18123-18128.

Cardoch, L., Day, J.W., Ibanez, C., 2002. Net primary productivity as an indicator of sustainability in the Ebro and Mississippi deltas. Ecol. Appl. 12, 1044-1055.

Chen, B., Zhang, X., Tao, J., Wu, J., Wang, J., Shi, P., Zhang, Y., Yu, C., 2014. The impact of climate change and anthropogenic activities on alpine grassland over the Oinghai-Tibet Plateau. Agric. Forest Meteorol. 189, 11-18.

Diaz, S., Fargione, J., Chapin III, F.S., Tilman, D., 2006. Biodiversity loss threatens human well-being. PLoS Biol. 4, e277.

Diaz, S., Lavorel, S., de Bello, F., Quetier, F., Grigulis, K., Robson, T.M., 2007. Incorporating plant functional diversity effects in ecosystem service assessments. Proc. Natl. Acad. Sci. U. S. A. 104, 20684-20689.

Dunne, T., Western, D., Dietrich, W.E., 2011. Effects of cattle trampling on vegetation, infiltration, and erosion in a tropical rangeland. J. Arid Environ. 75, 58-69.

Field, C.B., Randerson, J.T., Malmstrom, C.M., 1995. Global net primary production: combining ecology and remote sensing. Rem. Sens. Environ. 51, 74-88

Haberl, H., 1997. Human appropriation of net primary production as an environmental indicator: implications for sustainable development. Ambio 26, 143-146.

Haberl, H., Erb, K.H., Krausmann, F., 2014. Human appropriation of net primary production: patterns, trends, and planetary boundaries. Annu. Rev. Environ. Resour 39, 363-391.

Haberl, H., Erb, K.H., Krausmann, F., Gaube, V., Bondeau, A., Plutzar, C., Gingrich, S., Lucht, W., Fischer-Kowalski, M., 2007. Quantifying and mapping the human appropriation of net primary production in earth's terrestrial ecosystems. Proc. Natl. Acad. Sci. U. S. A. 104, 12942-12945.

Hafner, S., Unteregelsbacher, S., Seeber, E., Lena, B., Xu, X.L., Li, X.G., Guggenberger, G. Miehe, G., Kuzyakov, Y., 2012. Effect of grazing on carbon stocks and assimilate partitioning in a Tibetan montane pasture revealed by $13 \mathrm{CO} 2$ pulse labeling. Global Change Biol. 18, 528-538.

Han, J.J., Chen, J.Q., Han, G.D., Shao, C.L., Sun, H.L., Li, L.H., 2014. Legacy effects from historical grazing enhanced carbon sequestration in a desert steppe. J. Arid Environ. 107, 1-9.

Hawkes, C.V., Sullivan, J.J., 2001. The impact of herbivory on plants in different resource conditions: a meta-analysis. Ecology 82, 2045-2058.

Heinsch, F.A., Reeves, M., Votava, P., Kang, S., Milesi, C., Zhao, M., Glassy, J., Jolly, W.M., Loehman, R., Bowker, C.F., Kimball, J.S., Nemani, R.R., Running, S.W., 2003. User's Guide GPP and NPP (MOD17A2/A3) Products NASA MODIS Land Algorithm. MODIS Land Team.

Imhoff, M.L., Bounoua, L., Ricketts, T., Loucks, C., Harriss, R., Lawrence, W.T., 2004 Global patterns in human consumption of net primary production. Nature 429 , 870-873.

Jin, Y.F., Goulden, M.L., 2014. Ecological consequences of variation in precipitation: separating short-versus long-term effects using satellite data. Global Ecol. Biogeogr. 23, 358-370.

Krausmann, F., Erb, K.H., Gingrich, S., Haberl, H., Bondeau, A., Gaube, V., Lauk, C., Plutzar, C., Searchinger, T.D., 2013. Global human appropriation of net primary production doubled in the 20th century. Proc. Natl. Acad. Sci. U. S. A. 110, $10324-10329$

Lauenroth, W.K., Sala, O.E., 1992. Long-term forage production of North-American shortgrass steppe. Ecol. Appl. 2, 397-403.

Lauenroth, W.K., Wade, A.A., Williamson, M.A., Ross, B.E., Kumar, S., Cariveau, D.P., 2006. Uncertainty in calculations of net primary production for grasslands. Ecosystems 9, 843-851.

Leps, J., de Bello, F., Lavorel, S., Berman, S., 2006. Quantifying and interpreting functional diversity of natural communities: practical considerations matter. Preslia 78, 481-501

Leriche, H., LeRoux, X., Desnoyers, F., Benest, D., Simioni, G., Abbadie, L., 2003. Grass response to clipping in an African savanna: testing the grazing optimization hypothesis. Ecol. Appl. 13, 1346-1354.
Leriche, H., LeRoux, X., Gignoux, J., Tuzet, A., Fritz, H., Abbadie, L., Loreau, M., 2001 Which functional processes control the short-term effect of grazing on net primary production in grasslands? Oecologia 129, 114-124.

Lieth, H., 1975. Modeling the primary productivity of the world. In: Lieth, H., Whittaker, R.H. (Eds.), Primary Productivity of the Biosphere. Springer-Verlag, New York, USA, pp. 237-264.

Mao, D., Wang, Z., Li, L., Song, K., Jia, M., 2014. Quantitative assessment of humaninduced impacts on marshes in Northeast China from 2000 to 2011. Ecol. Eng. 68, 97-104

Millennium Ecosystem Assessment, 2005. Ecosystems and Human Well-being: Synthesis. Island Press, Washington, DC.

Ministry of Agriculture of the People's Republic of China, 2002. Calculation of proper carrying capacity of rangelands. NY/T 635-2002.

Pan, Y., Wu, J., Xu, Z., 2014. Analysis of the tradeoffs between provisioning and regulating services from the perspective of varied share of net primary production in an alpine grassland ecosystem. Ecol. Complex 17, 79-86.

Peters, D.P.C., Yao, J., Browning, D., Rango, A., 2014. Mechanisms of grass response in grasslands and shrublands during dry or wet periods. Oecologia 174, 1323 1334.

Peters, D.P.C., Yao, J., Sala, O.E., Anderson, J.P., 2012. Directional climate change and potential reversal of desertification in arid and semiarid ecosystems. Global Change Biol. 18, 151-163.

Potter, C.S., Randerson, J.T., Field, C.B., Matson, P.A., Vitousek, P.M., Mooney, H.A. Klooster, S.A., 1993. Terrestrial ecosystem production: a process model based on global satellite and surface data. Global Biogeochem. Cycles 7, 811-841.

Prentice, I.C., Cramer, W., Harrison, S.P., Leemans, R., Monserud, R.A., Solomon, A.M. 1992. A global biome model based on plant physiology and dominance, soi properties and climate. J. Biogeogr. 19, 117-134.

Raich, J.W., Rastetter, E.B., Melillo, J.M., Kicklighter, D.W., Steudler, P.A., Peterson, B.J., Grace, A.L., Moore, B., Vorosmarty, C.J., 1991. Potential net primary productivity in South-America - application of a global model. Ecol. Appl. 1, 399-429.

Reichmann, L.G., Sala, O.E., Peters, D.P.C., 2013. Precipitation legacies in desert grassland primary production occur through previous-year tiller density. Ecology 94 , 435-443.

Ruppert, J.C., Linstadter, A., 2014. Convergence between ANPP estimation methods in grasslands - a practical solution to the comparability dilemma. Ecol. Indic. 36 , 524-531.

Sala, O.E., Gherardi, L.A., Reichmann, L., Jobbagy, E., Peters, D., 2012. Legacies of precipitation fluctuations on primary production: theory and data synthesis. Philos. Trans. R. Soc. B-Biol. Sci. 367, 3135-3144.

Schonbach, P., Wan, H.W., Gierus, M., Bai, Y.F., Muller, K., Lin, L.J., Susenbeth, A. Taube, F., 2011. Grassland responses to grazing: effects of grazing intensity and management system in an Inner Mongolian steppe ecosystem. Plant Soil 340, 103-115.

Smith, W.K., Cleveland, C.C., Reed, S.C., Running, S.W., 2014. Agricultural conversion without external water and nutrient inputs reduces terrestrial vegetation productivity. Geophys. Res. Lett. 41, 2013 GL058857.

van Staalduinen, M., Dobarro, I., Peco, B., 2010. Interactive effects of clipping and nutrient availability on the compensatory growth of a grass species. Plant Ecol. 208, 55-64.

Vojtech, E., Loreau, M., Yachi, S., Spehn, E.M., Hector, A., 2008. Light partitioning in experimental grass communities. Oikos 117, 1351-1361.

Walter, J., Grant, K., Beierkuhnlein, C., Kreyling J., Weber, M., Jentsch, A, 2012 Increased rainfall variability reduces biomass and forage quality of temperate grassland largely independent of mowing frequency. Agric. Ecosyst. Environ. $148,1-10$.

Wang, L., Wang, D., Bai, Y., Jiang, G., Liu, J., Huang, Y., Li, Y., 2010a. Spatial distributions of multiple plant species affect herbivore foraging selectivity. Oikos 119, 401-408.

Wang, L., Wang, D.L., He, Z.B., Liu, G.F., Hodgkinson, K.C., 2010b. Mechanisms linking plant species richness to foraging of a large herbivore. J. Appl. Ecol. 47, 868875

Wang, L., Wang, D., Liu, J., Huang, Y., Hodgkinson, K.C., 2011. Diet selection variation of a large herbivore in a feeding experiment with increasing species numbers and different plant functional group combinations. Acta Oecol.-Int. J. Ecol. 37, 263-268.

Wise, M.J., Abrahamson, W.G., 2007. Effects of resource availability on tolerance of herbivory: a review and assessment of three opposing models. Am. Naturalist $169,443-454$

Wright, D.H., 1990. Human impacts on energy flow through natural ecosystems, and implications for species endangerment. Ambio 19, 189-194.

Wu, Y.B., Tan, H.C., Deng, Y.C., Wu, J., Xu, X.L., Wang, Y.F., Tang, Y.H., Higashi, T., Cui, X.Y., 2010. Partitioning pattern of carbon flux in a Kobresia grassland on the Qinghai-Tibetan Plateau revealed by field 13C pulse-labeling. Global Change Biol. 16, 2322-2333.

Xu, Z., Cheng, S., Zhen, L., Pan, Y., Zhang, X., Wu, J., Zou, X., Bijaya, G.C.D., 2013. Impacts of dung combustion on the carbon cycle of alpine grassland of the North Tibetan Plateau. Environ. Manage. 52, 441-449.

Zhao, W., Chen, S.P., Lin, G.H., 2008. Compensatory growth responses to clipping defoliation in Leymus chinensis (Poaceae) under nutrient addition and water deficiency conditions. Plant Ecol. 196, 85-99. 